\title{
Effectiveness of robotics fall prevention program among elderly in senior housings, Bangkok, Thailand: a quasi-experimental study
}

This article was published in the following Dove Medical Press journal:

Clinical Interventions in Aging

\author{
Natthawadee Maneeprom' \\ Surasak Taneepanichskul' \\ Alessio Panza' \\ Areerat Suputtitada ${ }^{2}$ \\ 'College of Public Health Sciences, \\ Chulalongkorn University, Bangkok \\ 10330, Thailand; ${ }^{2}$ Department of \\ Rehabilitation Medicine, Faculty of \\ Medicine, Chulalongkorn University, \\ Bangkok 10330, Thailand
}

\begin{abstract}
Objective: This study aimed at investigating the effectiveness of a robotic fall prevention program on knowledge, exercises, balance, and incidence of falls among elderly in senior housings.

Patients and methods: This is a quasi-experimental study. Sixty-four elderly in two senior housings in Bangkok with Barthel Index scale $\geq 12$, who had either at least one fall experience in the past 12 months and/or had Timed Up and Go (TUG) test $\geq 20$ seconds were recruited and purposively assigned to the intervention group (received a small robot-installed fall prevention software, personal coaching, and handbook, $n=32$ ) and control group (received only handbook, $n=32$ ). Outcomes were knowledge score evaluated by structured questionnaire through face-to-face interviews, number of exercises measured by self-recorded diary, and balance score assessed by TUG and Berg Balance Scale (BBS). The incidence of falls was assessed by face-to-face interviews. Both groups were assessed at baseline, 3rd, and 6th month after the intervention.
\end{abstract}

Results: There was a statistically significant improvement in knowledge mean score at 6 th month in both the groups. However, the intervention group showed faster increase in knowledge mean score than the control group at 3 rd month $(P<0.01)$. The intervention group showed a statistically significant higher number of exercises than the control group at 3rd and 6th month $(P<0.05)$. There was no statistically significant difference on TUG and BBS mean scores between the two groups at baseline, 3rd, and 6th month. However, the intervention group showed a statistically significant improvement in TUG and BBS at 6th month post-intervention $(P<0.01)$. There was one fall reported in the control group.

Conclusion: The robotic fall prevention program increased knowledge on fall prevention and promoted exercises and balance among elderly in senior housings.

Keywords: fall prevention robot, elderly, Timed Up and Go test, Berg Balance Scale, Thailand, senior housing

\section{Introduction}

Falls among elderly are a major health issue worldwide. One-third of elderly aged $>65$ years experienced fall each year. Prevalence of fall in elderly varies among settings. There is a higher prevalence of fall among elderly living in a long-term care institution than those who are living in a community. ${ }^{1-3}$ A previous study found that the prevalence of fall among elderly nursing home residents was ranged between $50 \%$ and $66 \%$, while among hospitalized patients it was found to be at $50 \% .{ }^{4}$ In Thailand, in 2014 , the prevalence of fall among elderly community-dwellers was $16.9 \% .^{5}$

Fall is the second leading cause of unintentional injury death, after road traffic injuries. ${ }^{6}$ An elderly who had experienced a fall tend to have 2-3 recurrences of falls. ${ }^{7}$
Taneepanichsku

College of Public Health Sciences,

Chulalongkorn University, Institute

Building 2-3, Soi Chulalongkorn 62,

Phyathai Rd, Pathumwan, Bangkok 10330,

Thailand

Tel +6622188193

Fax +66 22556046

Email surasakta@yahoo.com 
Falling in elderly is risky. Just one time of falling in the elderly can affect the health status and daily living activities, or can even be bedridden. Approximately one-third of falls leads to injury severity levels ranging from light to heavy. Falling is one of the major causes of admission in hospitals among elderly aged $\geq 65$ years. Elderly who have hip fracture from falling may have to stay at a hospital for over 20 days. The more comorbidity or higher aged the elderly is, the more hospital stay time. ${ }^{8}$

Few of the direct costs of fall are medication treatment, pharmacy, and cost of transportation to health centers. The average health system cost per one fall injury for elderly aged $\geq 65$ years has significantly increased. ${ }^{9,10}$ Indirect costs involve loss of man day work for a family member taking care of the elderly who fell. A previous study found the average lost earnings of 40,000 USD per year in the UK. ${ }^{11}$

Falls exponentially increase with age-related biological changes. The fall incidents increased twofold in elderly aged $>75$ years. ${ }^{12}$ Falling among elderly is going to be more challenging in the future. With a fast growing aging population worldwide, the number of elderly aged $>60$ years is growing faster than other age groups. Moreover, the oldest group of the population, aged $\geq 80$ years, is the fastest growing group and expected to be $20 \%$ of the overall elderly population in $2050 .^{4}$

Many fall prevention guidelines from WHO, ${ }^{4}$ Centers of Disease Control and Prevention (CDC), ${ }^{13}$ and Ministry of Public Health of Thailand ${ }^{8,14}$ indicate that the risk factors of fall are usually classified as intrinsic and extrinsic risk factors. Intrinsic risk factors of fall include a history of fall, walking and balance problems, less muscle strength, visual impairment, incontinent, receiving many medications, cognitive problems. Extrinsic risk factors are referred to environmental hazards such as a wet floor, slippery and uneven ground surface, inadequate lighting, and inappropriate clothing.

Fall can be prevented. ${ }^{13}$ A systematic review of fall prevention interventions among elderly dwelling in the community indicates that home-based exercise program, home modification, reducing medications, and intervention of visual problem solving were effective interventions to prevent falls. ${ }^{15}$

The Otago Exercise Program (OEP) is a recommended home-based exercise program for elderly in the community. ${ }^{16,17}$ It is an evidence-based fall prevention program which resulted from four separate control trials among 1,016 elderly in New Zealand. OEP was effective in reducing 35\% in both the number of falls and the number of injuries resulting from falls. ${ }^{16}$ The program is delivered by a physiotherapist or trained instructor with six home exercise visits, four telephone follow-ups, and monthly monitoring of the completed exercises and any fall incident over a 1-year period. Main features of the program compose of five leg muscle strengthening exercises and 12 balance retaining exercises, up to four levels of difficulty. The participants should exercise for $\sim 30$ minutes at least three times a week, and includes a walking plan for the rest day. Each participant receives a booklet with illustration and instructions for the exercises, one or more ankle cuff weights, calendar or diary to record their exercise or any falls. ${ }^{16}$ In Thailand, a fall prevention guideline $(2012)^{8}$ has also recommended exercise for fall prevention which is modified from OEP for elderly in the community.

Many technology-based interventions are also developed for fall prevention. A 2016 systematic review ${ }^{18}$ indicates that the wearable sensor and camera-based and floor sensors are installed in the living environment, which feed information back to the software monitoring the user's interactions with that environment.

Among wearable sensors for monitoring falls during static and dynamic tasks in healthy elderly, ${ }^{19}$ accelerometers and gyroscopes are widely used for fall risk assessment, fall prevention, and fall detection because they are low cost and sends reliable informative signals to the software. The most used body segment for positioning the sensors is the trunk.

There are limitations that wearable sensors are still in an experimental phase and the effect has not been conclusively validated. ${ }^{19}$ Camera-based and floor sensors have a limited range within the monitored environment. Preserving privacy of elderly is also a challenge for camerabased technology. ${ }^{18}$

Robotic technology has been developed for medicine and home care. Recently, Japan developed a Human Support Robot (HSR), operated remotely by patients themselves or by family and caregivers. The HSR can pick up objects off the floor and bring things down from the shelves. The nursing care robot lifts the elderly from bed into a wheelchair, or assist them to stand up. ${ }^{20}$ In Europe, a robot is synced with a smart home technology such as environmental sensors, which is installed in the house feeding information about the occupant's movements, alerting off-site caregivers in the event of a fall, and also provide physiological sensors to track health such as blood pressure. ${ }^{20}$ While in Thailand, Dinsow Mini ${ }^{\circledR}$ robot is developed for a home user. It provides entertainment function such as listening to music or watching a video. The robot is synchronized with the mobile application, so the users or caregivers could operate the robot from 
their own smartphone such as updating information, songs, and photos, and/or making a video call. ${ }^{21}$

However, the robotic technology, which focuses on behavioral change intervention specifically for fall prevention in Thailand is rare. This study aimed at investigating the effectiveness of robotic fall prevention program on knowledge score of fall prevention, number of exercises, balance score, and incidence of falls among elderly at risk of fall residing in senior housings in Bangkok, Thailand.

\section{Patients and methods}

\section{Sample size, study design, and procedure}

The sample size was calculated with two-tailed statistical hypothesis with effect size at $0.76,{ }^{22} \alpha$-error of probability at 0.05 , and a power of 0.80 . We used G-Power statistical analysis program version 3.1.9.2 to calculate the sample size of participants. The required number of sample size was 29 for each group, and $10 \%$ of participants were added to compensate for withdrawing or loss to follow-up during the intervention. Hence, the final number was 32 participants in each group $(\mathrm{N}=64)$.

To ensure the similarity of the living environment of participants between the intervention and control groups, the two senior housings were purposively sampled from the governmental bodies: Sawangkanivej and Ban Bang Khae. The facilities were designed for the convenience of the elderly such as wide doors for wheelchair, slop with handle, gym room, meeting room, yard, and garden. There are a routine nurse and physical therapist available at the health room at some specific time. The intervention and control groups were selected from different housings to ensure that there was no contamination of intervention between groups. There is $43.8 \mathrm{~km}$ distance between the two senior housings.

The fall risk screening conducted on all 350 residents in the two senior housings, followed the guideline from CDC. ${ }^{23}$ Elderly who said "yes" to any of the following questions: 1) fall experienced in the past 12 months, 2) feel unsteady when standing or walking, and 3) worries about falling, was evaluated fall risk by Timed Up and Go (TUG) test.

To be an eligible participant, an elderly had to pass the following inclusion criteria: 1 ) aged $\geq 60$ years, 2) can read and write Thai language, 3 ) presently physically active, measured by Barthel Index (BI) scale $\geq 12$ score,${ }^{24} 4$ ) considered at risk of fall by either a previous fall experienced in past 12 months and/or had TUG test $\geq 20$ seconds, ${ }^{14,23}$ and 5) lived in senior housing for at least 1 month. Among the total residents, 91 elderly were eligible to be subjects. Exclusion criteria of this study were elderly who had health problem that could not participate in this study, being diagnosed with cognitive impairment such as dementia, Alzheimer, or psychoses, hearing impairment, visual impairment which cannot be corrected by eyeglasses, and unwilling to join this study. Finally, 64 elderly were recruited in this study. Thirty-two participants residing in Sawangkanivej were purposively assigned to the intervention group and another 32 participants residing in Ban Bang Kae were purposively assigned to the control group (Figure 1).

Intervention in this study was a robotic fall prevention program, which composed of a small robot-installed fall prevention software together with personal coaching and a fall prevention handbook. The robot, Dinsow Mini ${ }^{\circledR}$ version M2070 was used in this study with $35 \mathrm{~cm}$ in height, $24 \mathrm{~cm}$ in length, $18 \mathrm{~cm}$ in width, and weighed $3.13 \mathrm{~kg}$. (Figure 2). The 8 " touchscreen was installed at the head section of the robot. The elderly can watch a video on this screen. Same as any other electric appliance, the robot needed to be plugged in.

In this study, we developed a fall prevention software from social cognitive theory (SCT), ${ }^{25}$ consumer information processing (CIP) model, ${ }^{26}$ and literature reviews. ${ }^{8,14,15}$ Many meetings were conducted between main research investigator, one physiotherapist, three elderly caregivers, and two software engineers to understand the need of the user and its feasibility in the software design. A preliminary survey was conducted in the two housings. Since Thai elderly (born before 1957) were not familiar with using new technologies, personal coaching was added into this program. Moreover, any equipment that relied on internet connectivity was not practically used among Thai elderly. Thus, many educational materials were embedded in the software that could be accessed without an internet connection.

Finally, the fall prevention software was provided with four videos on fall prevention and choosing appropriate walking assistive devices, two videos demonstrating how to make sandbag and choose an appropriate shoe, two videos on exercises, and 28 daily voice messages on fall prevention and daily exercise reminders.

SCT was used to develop a conceptual framework of this study in which fall prevention could occur in a social context with a dynamic and reciprocal interaction of the person, environment, and behavior. According to SCT, a person is able to perform a behavior through essential knowledge and skill. Thus, fall education was needed to implement this study. The participants learned fall prevention and exercises from video demonstrations displayed on the screen of the robot and a handbook with illustrations and instructions. 


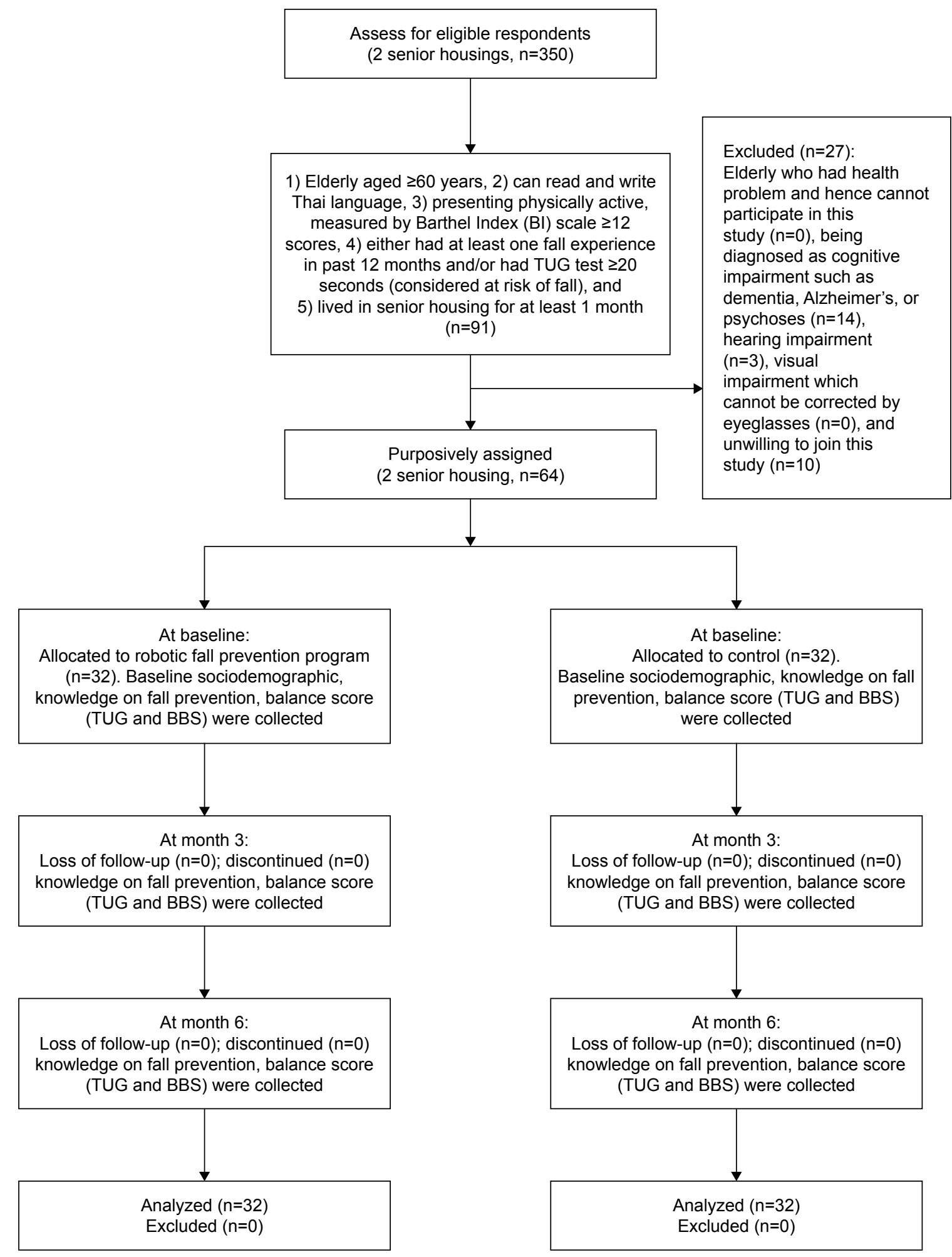

Figure I Flowchart of this study.

Abbreviations: BBS, Berg Balance Scale; TUG, Timed UP and Go.

Two exercise videos including light and advanced exercise levels were chosen from Ministry of Public Health of Thailand. ${ }^{27,28}$ The contents of exercises in these two videos were modified from the OEP, which proved effective in reducing the number of falls and number of injuries resulting from falls. ${ }^{16,29}$

Light exercise ${ }^{27}$ required some equipment to hold for support such as a bar or a stable table. The advanced exercise ${ }^{28}$ 


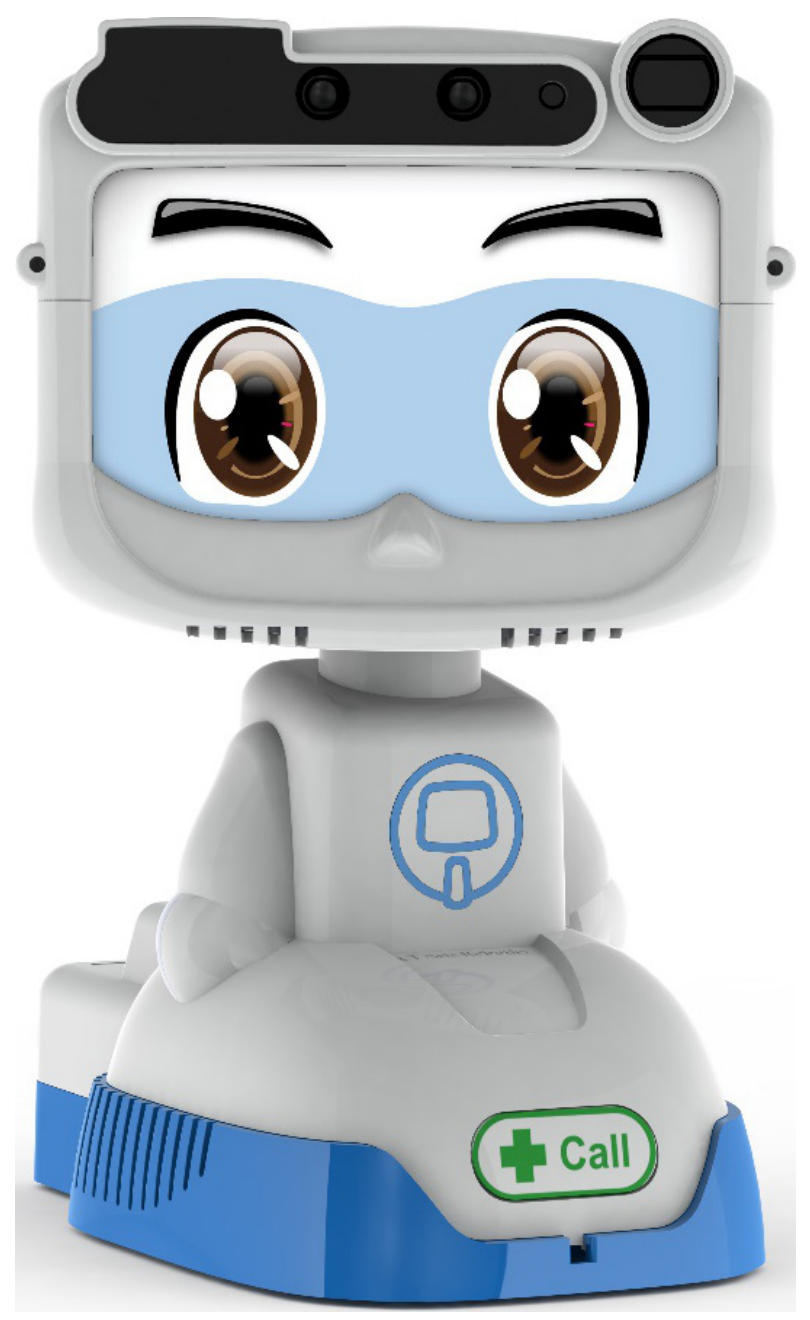

Figure 2 Dinsow Mini ${ }^{\circledR}$ robot. $^{21}$

Note: Copyright @2012. CT Asia Robotics Co. Ltd. Reproduced from CT Asia Robotics Co. L. Dinsow Mini 2012;20I2. Available from: http://www.ctasiarobotics. com/home/index.php. Accessed June 12, 2018. ${ }^{21}$

performed activities such as walking and turning around without support. Each participant was evaluated for balance by these following questions: ${ }^{8} 1$ ) can you perform activities of daily living (ADL) independently? 2) can you sit and stand independently? and 3) can you perform heel-to-toe standing? Elderly who said "no" to any of these questions was assigned to light level exercise. While elderly who said "yes" to all questions were assigned to advanced level exercise. Not only safety during exercise was considered, but also self-efficacy was promoted. The elderly had confidence to perform exercises successfully.

CIP was used to develop chunks of educational materials. Daily voice messages composed of 28 messages on fall prevention, which automatically notified daily at $8.00 \mathrm{PM}$, starting from the first message at day 1 to complete 28th message at day 28. Four videos on fall prevention education and choosing appropriate walking assistive devices were chosen from educational institutions. ${ }^{30-33}$ Two videos demonstrating how to make sandbag for exercise, and choosing appropriate shoe were filmed by paramedic principle investigator. ${ }^{34,35}$ Moreover, exercise reminder was developed and automatically notified at 8.00 AM.

\section{Implementation of the intervention}

We sent permission letters from Chulalongkorn University to the two senior housings. Then, invitation posters were pinned on the central board at the clubhouse and the office of the two senior housings, and staffs announced our project to their residents. Any resident who was interested in fall risk screening could join activities including a short interview and TUG test, $\sim 5$ minutes for each person. The elderly participants who met our inclusion criteria were invited to participate in this study.

The participants in the intervention group were scheduled date and time for setting the robots in their room for $\sim 40-60$ minutes. Principle investigator demonstrated how to use the robot, observed participants actually using it, and provided personalized feedback. Each participant received a robot-installed fall prevention software together with a handbook and personal coaching.

Personal coaching was conducted in the intervention group for $\sim 1$ hour, at the baseline, 2 nd, and 3rd month to make sure the participants could use the robot and perform exercises independently. Video education was discussed in the coaching session. In addition, principle investigator assisted the participants, who required some help, anytime during the 6-month study period. If a problem regarding using robot emerged, the principal investigator demonstrated using robot again until participants can use the robot independently. If a problem arises regarding the robot being broken or malfunction, the principal investigator replaced it with a new robot.

There was neither robot nor coaching in the control group. Participants in the control group received a fall prevention handbook with exactly the same content as the intervention group, and engaged in their daily routine activities such as walking and doing housework.

Baseline data on sociodemographic, comorbidities, fall experienced, and knowledge on fall prevention were obtained through face-to-face interviews using questionnaires. Balance scores were evaluated by the ability to perform task-oriented tests including TUG and Berg Balance Scale (BBS). Each participant, in both intervention and control groups, was advised appropriate exercise according to his/ her physical condition. All participants were taught how to self-record their exercise on the given exercise diary.

Knowledge on fall prevention and balance scores were assessed again at 3rd and 6th month after intervention. 
Principle investigator gave feedback of knowledge scores and balance scores to both intervention and control groups. Any questions regarding the program were discussed. The number of exercises was assessed at 3rd and 6th month from the self-recorded exercise diary. All participants were free to contact principle investigator any time throughout the 6-month study period.

All participants were interviewed face-to-face for the new fall event(s) during the study period at 3rd and 6th month after the intervention was implemented. The principle investigator rechecked incidence of falls by interviewing in-house nurse, caregiver, or staff of the two senior housings. All coaching and data collections were conducted by the main research investigator.

This study was conducted in accordance with the Declaration of Helsinki, approved by the Ethics Review Committee for Research Involving Human Research Subjects, Health Sciences Group, Chulalongkorn University (COA No 201/2560).

\section{Measurements}

\section{Sociodemographic questionnaire}

The sociodemographic questionnaire was used to interview baseline characteristic of participants and incidence of falls during the intervention period. It has four parts as follows: 1) demographic: sex, age, marital status, education, income, and source of income; ${ }^{36}$ 2) health: comorbidity, medication, eyesight problem, eyeglasses/contact lens utilization, and physical activities; ${ }^{8,14,36} 3$ ) environment: walking assistive devices and environmental hazards, $;^{8,14,36,37}$ and 4) experience of fall in the past 12 months prior to this study and new fall incident during the 6-month study period.

\section{$B$ I scale of $A D L$ - Thai version}

BI of ADL - Thai version was used to determine the level of physical activities ${ }^{24}$ with an excellent correlation with the Dynamic Gait Index $(r=0.067)$ among the elderly population, ${ }^{38}$ high inter-rater reliability between therapists, ${ }^{39}$ and the inter-class correlation was $0.87 .{ }^{24}$ The BI is composed of ten items including 1) feeding, 2) grooming, 3) transfer, 4) toilet use, 5) mobility, 6) dressing, 7) stairs, 8) bathing, 9) bowels, and 10) bladder. The score is ranged from 1 to 20. The interpretation of the Thai version of BI scale was made according to cutoff of points: ${ }^{24} 0-4$ scores, dependent or bedridden; 5-11 scores, partial dependent; and $\geq 12$ scores, independent or active elderly.

\section{TUG}

TUG is widely used for fall risk screening with sensitivity at $73.7 \%$ and specificity at $65.8 \% .{ }^{40}$ It has good validity, ${ }^{41}$ and is reliable, valid, and easy-to-administer for assessing balance, ${ }^{42}$ and is also recommended for fall risk screening in elderly by Ministry of Public Health of Thailand ${ }^{43}$ First, the elderly were asked to sit comfortably on a straight-backed chair with both feet placed on the ground. Placing an object at $3 \mathrm{~m}$ in front of the chair, the elderly were instructed to rise from the chair, without trying to put hands for support, and walk straight, turn around over the placed object, walk back to the chair, and sit down on the chair. The elderly should walk as fast as they can. The examiner starts the stop watch from the time of asking the elderly to rise up until the elderly walked back and sat down. A cutoff of point $\geq 20$ seconds is considered as having the risk of fall for Thai elderly. ${ }^{14}$

\section{BBS}

BBS is widely used for assessing balance. It can also be used for patients with neuromuscular disease and lowerlimb amputation. ${ }^{44}$ In Thailand, Ministry of Public Health recommends BBS for fall risk assessment in the elderly. ${ }^{43}$ The sensitivity in predicting fall was 0.72 , specificity was 0.73 , and accuracy was $0.84 .{ }^{45}$ It is 14 task-oriented screening test including 1) sitting to standing, 2) standing unsupported, 3) sitting with back unsupported but feet supported on the floor or on a stool, 4) standing to sitting, 5) transfers, 6) standing unsupported with eyes closed, 7) standing unsupported with feet together, 8) reaching forward with outstretched arms while standing, 9) pick up object from the floor from a standing position, 10) turning to look behind over left and right shoulders while standing, 11) turn 360 degrees, 12) placing alternative foot on step or stool while standing unsupported, 13) standing unsupported one foot in front, and 14) standing on one leg. The item-level is ranged from 0 to 4 , depending on the ability to perform the tasks. The score is ranged from 0 to 56 .

\section{Knowledge on fall prevention}

The fall prevention questionnaire was developed from literature review ${ }^{14}$ and tested on a pilot group. The Cronbach's alpha coefficient was 0.77 . It is composed of 31 items, and was rated 0 or 1 score. The total score ranged from 0 to 31 . Interpretation was based on a mean score: $<$ mean and $\geq$ mean.

\section{Number of exercises}

All participants were given a blank calendar template, considered as an exercise diary, which has be ticked on the day that they do exercise based on the given video and/or handbook guideline. The exercise diary was assessed by self-report and collected at 3rd and 6th month after the intervention was performed. 


\section{Statistical analysis}

The data were analyzed by using SPSS (for Windows) version 20. Descriptive statistics were used to describe the sociodemographic of participants. Categorical data were presented in frequency and percentage. Numerical data were presented in frequency, percentage, mean, and SD. Chi-squared test was used for baseline comparison. Independent $t$-test was used to determine the statistically significant difference in knowledge score, number of exercises, TUG, BBS, and incidents of fall between intervention and control groups at baseline, 3rd, and 6th month after the intervention was implemented. Repeated measures ANOVA was performed to determine statistically significant difference in knowledge score, TUG, and BBS at baseline, 3rd, and 6th month within the groups. Bonferroni post hoc analysis was performed for pairwise comparisons in each group. Paired t-test was used to determine statistically significant difference on number of exercises at 3rd month compared to 6th month within the group. A $P$-value of $<0.05$ was considered as statistically significant in this study.

\section{Result}

\section{Sociodemographic and health characteristics}

The data on sociodemographic and health characteristics of participants are presented in Table 1. Majority of participants (79.7\%) were female, $54.7 \%$ were aged $60-75$ years, $54.7 \%$ had secondary and university education background, and $85.9 \%$ had enough income. More than half of the participants (51.6\%) had $\geq 3$ comorbidities. Most of the participants (79.7\%) had medication risk using $\geq 4$ medications: seizure, antihypertensives, sedative, and hypnotic. Moreover, $84.4 \%$ of participants had eyesight problem. Mean score and SD of TUG was 20.7 \pm 7.7 ; BBS score was 45.3 \pm 10.6 ; and knowledge score was $25.8 \pm 4.5$. Most of the participants $(70.3 \%)$ had physical activities for $>30$ minutes $\geq 3$ times/week, and $70.3 \%$ had at least one fall experience in the past 12 months prior to this study. There was no statistically significant difference in baseline characteristics among the intervention and the control groups (Table 1).

\section{Knowledge on fall prevention}

Both intervention and control groups showed a statistically significant improvement in knowledge mean score $(P<0.05)$. However, there was no significant difference between intervention and control groups at baseline, 3rd, and 6th month after the intervention. Interestingly, the intervention group showed a faster statistically significant improvement in knowledge mean score than those in the control group at the $3 \mathrm{rd}$ month $(P=0.026$; Table 2$)$.

\section{Number of exercises}

The intervention group showed a statistically significant higher number of exercises than the control group at 3rd and 6th month $(P<0.05)$. Moreover, the intervention group showed a statistically significant increment number of exercises over time $(P<0.05$; Table 2$)$.

\section{Balance}

There was no statistically significant difference in TUG and BBS mean score between the two groups at baseline, 3rd, and 6th month. However, the intervention group revealed statistically significant improvement in both TUG and BBS at 6th month after the intervention was performed $(P<0.01$; Table 2).

\section{Incidence of falls}

During the 6-month study period, there was one fall incident in the control group, whereas no fall incident in the intervention group. The fall incident rate of participants in the control group was 0.06 person-year. The elderly reported that the fall happened during the walk and the knee collapsed, but it did not amount to injuries. There were no falls or injuries associated with performing the exercise fall prevention program.

\section{Result from coaching}

From the researcher's observation and interview, the elderly in the intervention group were excited about using the robot by participating in setting the robot and watching videos provided in the program, while elderly in the control group did not show interest in using the handbook.

All participants in the intervention group were scheduled coaching by the same principle investigator throughout the study period to develop trust. In the first 2 months, the elderly rarely used the robot because they forgot "how to" use it, thus teaching was repeated many times to ensure elderly could use the robot independently.

The results from coaching found that few functions were not feasible with user behavior. From the interview it was gathered that the elderly switched off and unplugged the robot when they do not use it. The elderly reported the irregular use of alarm functions including daily voice messages and exercise reminders because they often forgot to switch on the robot at 8.00 AM and 8.00 PM.

\section{Discussion}

The robotic fall prevention program in this quasi-experimental study, which composed of a small robot-installed fall prevention software together with personal coaching and fall prevention handbook can improve knowledge on fall 
Table I Baseline comparison on sociodemographic characteristics of participants $(n=64)$

\begin{tabular}{|c|c|c|c|c|c|c|}
\hline \multirow[t]{2}{*}{ Variables } & \multicolumn{2}{|c|}{ Intervention ( $\mathbf{N}=\mathbf{3 2})$} & \multicolumn{2}{|c|}{ Control $(\mathrm{N}=32)$} & \multirow[t]{2}{*}{$\chi^{2}$} & \multirow[t]{2}{*}{$P$-value } \\
\hline & $\mathbf{N}$ & $\%$ & $\mathbf{N}$ & $\%$ & & \\
\hline \multicolumn{7}{|l|}{ Demographics } \\
\hline \multicolumn{7}{|l|}{ Sex } \\
\hline Female & 24 & 37.5 & 27 & 42.2 & 0.869 & 0.351 \\
\hline Male & 8 & 12.5 & 5 & 7.8 & & \\
\hline \multicolumn{7}{|c|}{ Age (years), mean $\pm S D=74.4 \pm 9.3$} \\
\hline$\geq 76$ & 13 & 20.3 & 16 & 25.0 & 0.567 & 0.451 \\
\hline $60-75$ & 19 & 29.7 & 16 & 25.0 & & \\
\hline \multicolumn{7}{|l|}{ Education } \\
\hline High school and above & 20 & 31.3 & 15 & 23.4 & 1.576 & 0.209 \\
\hline Primary school & 12 & 18.8 & 17 & 26.6 & & \\
\hline \multicolumn{7}{|l|}{ Income } \\
\hline Not enough & 2 & 3.4 & 7 & 10.9 & 3.232 & 0.072 \\
\hline Enough & 30 & 46.9 & 25 & 39.1 & & \\
\hline \multicolumn{7}{|l|}{ Comorbidities } \\
\hline$\geq 3$ & 17 & 26.6 & 16 & 25.0 & 0.063 & 0.802 \\
\hline$<3$ & 15 & 23.4 & 16 & 25.0 & & \\
\hline \multicolumn{7}{|l|}{ Medication risk } \\
\hline Yes & 23 & 35.9 & 28 & 43.8 & 2.413 & 0.120 \\
\hline No & 9 & 14.1 & 4 & 6.3 & & \\
\hline \multicolumn{7}{|l|}{ Physical functions } \\
\hline \multicolumn{7}{|l|}{ Eyesight problem } \\
\hline Yes & 27 & 42.2 & 27 & 42.2 & 0.000 & 1.000 \\
\hline No & 5 & 7.8 & 5 & 7.8 & & \\
\hline \multicolumn{7}{|l|}{ TUG, mean $\pm S D=20.7 \pm 7.7$} \\
\hline$\geq$ mean & 13 & 20.3 & 12 & 18.8 & 0.066 & 0.798 \\
\hline$<$ mean & 19 & 29.7 & 20 & 31.3 & & \\
\hline \multicolumn{7}{|c|}{ BBS, mean $\pm S D=45.3 \pm 10.6$} \\
\hline$\geq$ mean & 18 & 28.1 & 17 & 26.6 & 0.063 & 0.802 \\
\hline$<$ mean & 14 & 21.9 & 15 & 23.4 & & \\
\hline \multicolumn{7}{|c|}{ Physical activities $>30$ minutes, } \\
\hline \multicolumn{7}{|c|}{$\geq 3$ times/week } \\
\hline Yes & 26 & 40.6 & 19 & 29.7 & 3.668 & 0.055 \\
\hline No & 6 & 9.4 & 13 & 20.3 & & \\
\hline \multicolumn{7}{|c|}{ Knowledge on fall prevention: } \\
\hline$\geq$ mean & 17 & 26.6 & 21 & 32.8 & 1.036 & 0.309 \\
\hline$<$ mean & 15 & 23.4 & 11 & 17.2 & & \\
\hline \multicolumn{7}{|l|}{ Environmental hazards } \\
\hline$\geq 2$ & 12 & 18.8 & 14 & 21.9 & 0.259 & 0.611 \\
\hline$<2$ & 20 & 31.3 & 18 & 28.1 & & \\
\hline \multicolumn{7}{|l|}{ Fall experienced } \\
\hline Yes & 23 & 35.9 & 22 & 34.4 & 0.075 & 0.784 \\
\hline No & 9 & 14.1 & 10 & 15.6 & & \\
\hline
\end{tabular}

Note: Significant at $P<0.05$.

Abbreviations: BBS, Berg Balance Scale; TUG, Timed UP and Go.

prevention, promote exercises activity, and enhance balance among the participants.

Both intervention and control groups showed statistically significant improvements in knowledge mean score. The result from our study indicates that both handbook and robotic program have successfully improved knowledge score on fall prevention among participants. However, the intervention group reveals a faster increment on knowledge mean score than the control group at 3rd month after the intervention was performed.

In the intervention group, the daily voice message to convey knowledge on fall prevention was setup at 8.00 PM. Although the participant often forgot to switch on the robot at 8.00 PM, they still received the benefit from the video 
Table 2 Multiple comparisons on knowledge, number of exercises, TUG, BBS, and incidence of falls within and between groups ( $\mathrm{n}=64)$

\begin{tabular}{|c|c|c|c|c|c|}
\hline \multirow[t]{2}{*}{ Variable measures } & \multicolumn{2}{|c|}{ Intervention group $(\mathrm{N}=32)$} & \multicolumn{2}{|c|}{ Control group ( $\mathrm{N}=32$ ) } & \multirow[t]{2}{*}{$P$-value } \\
\hline & Mean & SD & Mean & SD & \\
\hline \multicolumn{6}{|l|}{ Knowledge } \\
\hline Baseline & 25.25 & 4.24 & 26.406 & 4.79 & 0.310 \\
\hline Month 3 & 26.94 & 4.20 & 26.469 & 4.19 & 0.657 \\
\hline Month 6 & 27.78 & 3.57 & 27.500 & 4.37 & 0.779 \\
\hline$P$-value & $<0.001$ & & 0.029 & & \\
\hline Bonferroni post hoc analysis ${ }^{\mathrm{a}}$ & $A(P=0.026)$ & & $\mathrm{A}(P=1.000)$ & & \\
\hline & $\mathrm{B}(P<0.00 \mathrm{I})$ & & $B(P=0.550)$ & & \\
\hline & $C(P=0.076)$ & & $C(P=0.025)$ & & \\
\hline \multicolumn{6}{|l|}{ Numbers of exercises } \\
\hline Month 3 & 10.28 & $|7.0|$ & 1.75 & 7.02 & 0.011 \\
\hline Month 6 & $|8.4|$ & 24.00 & 6.50 & 15.22 & 0.021 \\
\hline$P$-value ${ }^{\mathrm{a}}$ & $0.04 I^{b}$ & & $0.080^{\mathrm{b}}$ & & \\
\hline \multicolumn{6}{|l|}{ TUG } \\
\hline Baseline & 20.95 & 7.62 & 20.47 & 7.78 & 0.806 \\
\hline Month 3 & 20.37 & 6.88 & 20.38 & 7.81 & 0.995 \\
\hline Month 6 & 19.54 & 7.68 & 20.87 & 8.12 & 0.504 \\
\hline$P$-value & 0.005 & & 0.247 & & \\
\hline Bonferroni post hoc analysis ${ }^{a}$ & $A(P=0.287)$ & & $A(P=0.372)$ & & \\
\hline & $B(P=0.004)$ & & $B(P=1.000)$ & & \\
\hline & $C(P=0.032)$ & & $C(P=1.000)$ & & \\
\hline \multicolumn{6}{|l|}{ BBS } \\
\hline Baseline & 44.84 & 10.67 & 45.66 & 10.64 & 0.761 \\
\hline Month 3 & 45.47 & 10.29 & 45.94 & 10.64 & 0.858 \\
\hline Month 6 & 46.97 & 10.56 & 44.19 & 11.57 & 0.319 \\
\hline$P$-value & 0.005 & & 0.222 & & \\
\hline Bonferroni post hoc analysis ${ }^{a}$ & A $(P=0.408)$ & & $A(P=1.000)$ & & \\
\hline & $B(P=0.005)$ & & $B(P=0.746)$ & & \\
\hline & $C(P=0.007)$ & & $C(P=0.416)$ & & \\
\hline
\end{tabular}

Notes: $\mathrm{A}=$ baseline vs month $3 ; \mathrm{B}=$ baseline vs month $6 ; \mathrm{C}=$ month 3 vs month 6 ; a Significant at $\mathrm{P}<0.05$; ${ }^{\text {bPaired }} t$-test. All variables were analyzed using independent $t$-test and repeated measures ANOVA.

Abbreviations: BBS, Berg Balance Scale; TUG, Timed Up and Go.

education that is provided in the software. The faster increment of knowledge mean score may be due to the interest of the elderly toward the program. From the researcher's observation and interview, the elderly in the intervention group were excited about using the robot. The attraction of the intervention affects participants' motivation to being engaged in the program. This notion was supported by previous literature in the USA, $2009^{46}$ that stated that videos have the potential to grab learner's attention. Moreover, a previous study ${ }^{47}$ conducted on fall prevention education among inpatients in Australia, 2009 found that delivery video disc compared to a written workbook is more likely to achieve self-perceived risk of falling and higher levels of confidence and motivation to engage in self-protective strategies than participants who received the written workbook. The increment of knowledge mean score was also in line with a systematic review of $2013,{ }^{48}$ which suggested that an intensive face-to-face falls education program with multimedia materials should be considered for educating elderly patients during and after hospitalization.

The intervention group shows the higher number of exercises than the control group both at 3rd and 6th month. The exercise reminder was setup at $8.00 \mathrm{AM}$. Even when the elderly forgot to switch on the robot at $8.00 \mathrm{AM}$, they still got the benefit from videos and coaching. Thus, these participants were more adherent to exercise than the control group. This notion is supported with a previous qualitative study $^{48}$ of 2016, which indicated that the adherence to exercise could be enhanced by increasing the attractiveness of exercise programs, providing a model or feedback, and the feeling of being supported by care providers. Elderly patients prefer the possibility of being guided or supervised when doing exercise, and regularly checked and discussed with their care providers.

The intervention group shows a statistically significant improvement in the number of exercises after 6 months 
post-intervention. These may be due to participants becoming more familiar with using the robot. According to personal coaching, the elderly were not familiar using the robot in the first few months. After many repeated training and coaching, they could turn on and operate robot by themselves. Thus, the trend of exercise is increasing at 6th month compared to $3 \mathrm{rd}$ month.

There was no statistically significant difference in balance score between intervention and control groups at baseline, $3 \mathrm{rd}$, and 6th month after the intervention was performed. The possible reason why the participants in our control group could maintain their balance might be that they were engaged in other exercise activities such as walking, jogging, and arm swing, hence the balance score between intervention and control groups were not different.

The intervention group showed statistically significant improvements in balance with both TUG and BBS at 6th month post-intervention. The improvement in TUG and BBS mean scores in the intervention group is correspondent with number of exercises (Table 2). The intervention group performed more exercises than the control group, and eventually increased their balance score.

In this study, we chose exercise videos which were modified from the OEP, ${ }^{27,28}$ and we innovated a robotic program together with coaching and handbook. The improvement of balance in this study is correspondent with previous studies on OEP in Iran (2016), ${ }^{49}$ New Zealand (2003), ${ }^{16}$ and a systematic review (2010). ${ }^{29}$ Moreover, the finding of this study is also correspondent with recent studies in $\mathrm{USA}^{50,51}$ that conducted another delivery method of Otago exercise by the non-physical therapist. The data suggest that the action of doing the exercises may be the essential element of the OEP, providing opportunities to develop and test new delivery models.

One fall incident happened in the control group during the 6-month study period. Fall happened while the participant was walking in the community. The fall incidence rate of participants in the control group was 0.06 person-year or 62.49 per 1,000 person-year. There were no falls or injuries associated with performing the exercise program in both groups. The robotics program was implemented safely among the participants.

\section{Strengths, limitations, and practical recommendations}

The first strength of this study is that the quasi-experimental study was used to investigate the effectiveness of robotic fall prevention program in a real-life environment. The second strength is the $100 \%$ follow-up rate of all participants in both intervention and control groups. Thus, we can ensure the power of statistics at 0.80 . The third strength is that the validated and reliable measurement tools on balance were used in this study. ${ }^{41,42,45,52}$ And the fourth strength is that the education videos were chosen from trustable sources: exercise videos ${ }^{27,28}$ from the Ministry of Public Health, and fall prevention videos from educational institutions. ${ }^{30-33}$

However, some limitations existed in this study. First was the limitation of time. As fall incidence was found only $0.3-1.6$ falls/year/person, ${ }^{12}$ further study is recommended to take a longer period of time. Second, hardware components such as a small screen or low volume speaker was considered as a limitation. The future software and hardware developed for elderly should be more user-friendly by providing a wider screen on the robot, television screen connection, louder voice adjustable, and having a hearing equipment connection.

As a practical recommendation, a technology designed for the elderly should be considered with the behavior of the user in mind. The elderly switches off and unplug the robot when they do not use it. Thus, chargeable robot or embedded battery should be considered to ensure all-time functioning of the robot. Moreover, Thai elderly are not familiar with using new technologies. Thus, adoption of this program should come together with three components: robot-installed fall prevention program, fall prevention handbook, and coaching session from trained staff or caregiver.

This study provides an alternative delivering model of fall prevention intervention by using the robot. This innovation is in correspondence with a future trend of shrinkage of child population and increase of the elderly globally. ${ }^{53}$ Innovationassisted elderly is more important in the future.

\section{Conclusion}

The robotic fall prevention program, which composed of a small robot-installed fall prevention software together with personal coaching and fall prevention handbook, can increase knowledge on fall prevention, promote exercises, and improve balance among physically active elderly who is at risk of fall, residing in senior housings.

\section{Acknowledgments}

This study was funded by the Thailand Research Fund and Scholarship from the Graduate School, Chulalongkorn University to commemorate the 72nd Anniversary of His Majesty King Bhumibol Adulyadej and the 90th Anniversary Chulalongkorn University (Ratchadaphiseksomphot Endowment Fund). 


\section{Disclosure}

The authors report no conflicts of interest in this work.

\section{References}

1. Wu H, Ouyang P, Hong Wu PO. Fall prevalence, time trend and its related risk factors among elderly people in China. Arch Gerontol Geriatr. 2017;73:294-299.

2. Buckinx F, Croisier JL, Reginster JY, et al. Prediction of the incidence of falls and deaths among elderly nursing home residents: the senior study. J Am Med Dir Assoc. 2018;19(1):18-24.

3. Burton E, Lewin G, O'Connell H, Hill KD. Falls prevention in community care: 10 years on. Clin Interv Aging. 2018;13(13):261-269.

4. Ageing and life-course: Falls prevention in older age. World Health organization (WHO); 2016. Available from: http://www.who.int/ageing/ projects/falls_prevention_older_age/en/. Accessed May 17, 2016.

5. Wichai Aekplakarn. Thai National health Examination Survey. In: 5th ed. Nonthaburi, Thailand: Health Systems Research Institute (HSRI); 2014. Available from: http://thaitgri.org/?p=37869. Accessed September 12, 2018.

6. Falls. World Health Organization; 2018. Available from: http://www. who.int/news-room/fact-sheets/detail/falls. Accessed June 12, 2018.

7. National Center for Injury Prevention and Control. Preventing Falls: A Guide to Implementing Effective Community-Based Fall Prevention Programs. Atlanta, GA; 2015. Available from: https://www.cdc. gov/homeandrecreationalsafety/falls/community_preventfalls.html. Accessed October 29, 2018

8. Thanyaluck Anothaisinthawee ST, Srisawan P, Yothasamut C. Fall Prevention Medication. Bangkok: Research Institution and Elderly Development Foundation; 2012. Available from: www.thaitgri.org. Accessed May 30, 2016.

9. Hendrie D. Injury in Western Australia: The Health System Costs of Falls in Older Adults in Western Australia. Perth, Western Australia: Western Australian Government; 2003.

10. Nurmi I, Lüthje P. Incidence and costs of falls and fall injuries among elderly in institutional care. Scand J Prim Health Care. 2002;20(2):118-122.

11. The University of York. The Economic Cost of Hip Fracture in the UK. England: Health Promotion; 2000.

12. Rubenstein LZ. Falls in older people: epidemiology, risk factors and strategies for prevention. Age Ageing. 2006;35(suppl_2):ii37-ii41.

13. Thomas R. Frieden DH, Baldwin G, Dellinger A, Lee R. Preventioning Falls: A Guide to Implementing Effective Community-Based Fall Prevention Programs. 2nd ed. Atlanta, GA: Centers for Disease Control and Prevention, National Center for Injury Prevention and Control; 2015.

14. Areerat Suphutitada RB, Sathanon P. Elderly Handbook: Good Walking, No Falling Nonthaburi Health Systems Research Institute (HSRI); 2016. Available from: https://www.hsri.or.th/researcher/media/printedmatter/detail/7256. Accessed September 10, 2018.

15. Gillespie LD, Robertson MC, Gillespie WJ, Sherrington C, et al. Interventions for preventing falls in older people living in the community. Cochrane Database Syst Rev. 2012;9:CD007146.

16. A John Campbell MCR. Otago Exercise Programme to Prevent Falls in Older Adults. New Zealand: Otago Medical School, University of Otago; 2003.

17. UK A. Falls Prevention Exercise - Following the Evidence. UK; 2013. Available from: www.ageuk.org.uk. Accessed August 12, 2018.

18. Hamm J, Money AG, Atwal A, Paraskevopoulos I. Fall prevention intervention technologies: a conceptual framework and survey of the state of the art. J Biomed Inform. 2016;59:319-345.

19. Rucco R, Sorriso A, Liparoti M, et al. Type and location of wearable sensors for monitoring falls during static and dynamic tasks in healthy elderly: a review. Sensors (Basel). 2018;18(5):1613.

20. Robots are ready and welcome to assist the elderly. 2016. Available from: http://www.scmp.com/native/tech/topics/premier-living/article/1867828/robots-are-ready-and-welcome-assist-elderly. Accessed November 10, 2016.
21. CT Asia Robotics Co. L. Dinsow Mini 2012; 2012. Available from: http://www.ctasiarobotics.com/home/index.php. Accessed June 12, 2018.

22. Piphatvanitcha N. The Effect of a Fall Prevention Program on Gait and Balance of Community - Dwelling Elders. Nursing Sciences. Bangkok: Chulalongkorn University; 2016.

23. Centers for Disease Control and Prevention. Algorithm for fall risk screening, assessment, and intervention. In: Center for Disease Control and Prevention NCfipac, editor. USA: Center for Disease Control and Prevention, National Center for Injury Prevention and Control; 2017.

24. Rm PD, Prasertporn J, Somluck P, Saowaluck J, Ampai Y. The interrater reliability of Barthel index (Thai version) in stroke patients. J Thai Rehabil. 2006;16(1):1-9.

25. Behavioral Change Models: The Social Cognitive Theory. Boston University School of Public Health; 2013. Available from: http:// sphweb.bumc.bu.edu/otlt/MPH-Modules/SB/BehavioralChangeTheories/BehavioralChangeTheories5.html. Accessed February 2, 2019.

26. Bettman JR. Methods for Analyzing Consumer Information Processing Models. Paper presented at: SV - Proceedings of the Second Annual Conference of the Association for Consumer Research 1971. Labovitz School of Business \& Economics, University of Minnesota Duluth.

27. HITAP Thai. Light exercise of fall prevention in elderly Health Intervention and Technology Assessment Program. Thailand: Ministry of Public Health; 2016.

28. HITAP Thai. Advance exercise of fall prevention in elderly. Health Intervention and Technology Assessment Program. Thailand: Ministry of Public Health; 2014.

29. Thomas S, Mackintosh S, Halbert J. Does the 'Otago exercise programme' reduce mortality and falls in older adults?: a systematic review and meta-analysis. Age Ageing. 2010;39(6):681-687.

30. Faculty of Medicine Siriraj Hospital MU. Fall prevention in elderly. Bangkok: Siriraj Pr; 2008.

31. Taninnit Leerapun. How to use cane for knee pain. Faculty of Medicine Chiang Mai: Chiang Mai University; 2016.

32. TV program Happy body hm. Walker. dmc tv; 2014. Available from: https://www.youtube.com/watch? $\mathrm{v}=$ aoHrovMfi5Y\&t=73s. Accessed January 12, 2018.

33. Department of Rehabilitation. How to use wheel chair for caregiver. Department of Rehabilitation, Faculty of Medicine. Chiang Mai: Chiang Mai Univerity; 2016.

34. Maneeprom N. Choosing appropriate shoe. Research Project Fall Prevention in Elderly, College of Public Health Sciences. Bangkok: Chulalongkorn University; 2017.

35. Maneeprom N. Making sand bag Research Project Fall Prevention in Elderly, College of Public Health Sciences. Bangkok: Chulalongkorn University; 2017.

36. Currie L. Fall and Injury Prevention. 2008. In: Hughes RG, editor. Patient Safety and Quality: An Evidence-Based Handbook for Nurses. Rockville: Agency for Healthcare Research and Quality (US).

37. Checklist for safety: A home fall prevention checklist for older adults Center for Disease Control and Prevention, National Center for injury prevention and control, U.S. Department of Health \& Human Services; 2016. Available from: https://www.cdc.gov/steadi/. Accessed April 2017.

38. Shumway-Cook A, Baldwin M, Polissar NL, Gruber W. Predicting the probability for falls in community-dwelling older adults. Phys Ther. 1997;77(8):812-819.

39. Barthel Index (BI). Available from: https://commondataelements.ninds. nih.gov/Doc/NOC/Barthel_Index_NOC_Public_Domain.pdf. Accessed September 21, 2015

40. Tiago S, Alexandre DMM, Natália CR, Simone KM. Accuracy of Timed Up and Go Test for screening risk of falls among community-dwelling elderly. Rev Bras Fisioter. 2012;16(5):381-388.

41. Sebastião E, Sandroff BM, Learmonth YC, Motl RW. Validity of the timed up and Go test as a measure of functional mobility in persons with multiple sclerosis. Arch Phys Med Rehabil. 2016;97(7): 1072-1077. 
42. Chan PP, Si Tou JI, Tse MM, Ng SS. Reliability and validity of the timed up and Go test with a motor task in people with chronic stroke. Arch Phys Med Rehabil. 2017;98(11):2213-2220.

43. Institute of Geriatric Medicine. Medical practice guideline for prevention/ evaluation fall in elderly Thailand Health Department, Ministry of Public Health, Thailand 2008. Available from: www.dms.moph.go.th/dmsweb/ cpgcorner/2009021784231.pdf. Accessed February 2, 2019. Thai

44. Major MJ, Fatone S, Roth EJ. Validity and reliability of the Berg balance scale for community-dwelling persons with lower-limb amputation. Arch Phys Med Rehabil. 2013;94(11):2194-2202.

45. Park SH, Lee YS, Seong-Hi Park Y-SL. The diagnostic accuracy of the Berg balance scale in predicting falls. West J Nurs Res. 2017;39(11): $1502-1525$.

46. Berk RA. Multimedia teaching with video clips: TV, movies, YouTube, and mtvU in the College classroom. Int J Technol Teach Learn. 2009; 5(1): $1-21$.

47. Sm A-MH, Hoffmann T, Hill K. A randomized trial comparing digital video disc with written delivery of falls prevention education for older patients in hospital. J Am Geriatr Soc. 2009;57(8):1458-1463.

48. Palazzo C, Klinger E, Dorner V, et al. Barriers to home-based exercise program adherence with chronic low back pain: patient expectations regarding new technologies. Ann Phys Rehabil Med. 2016;59(2): $107-113$.
49. Dadgari A, Aizan Hamid T, Hakim MN, et al. Randomized control trials on Otago exercise program (OEP) to reduce falls among elderly community dwellers in Shahroud, Iran. Iran Red Crescent Med J. 2016;18(5):e26340.

50. Shubert TE, Smith ML, Goto L, Jiang L, Ory MG. Otago exercise program in the United States: comparison of 2 implementation models. Phys Ther. 2017;97(2):187-197.

51. Shubert TE, Goto LS, Smith ML, Jiang L, Rudman H, Ory MG. The Otago exercise program: innovative delivery models to maximize sustained outcomes for high risk, Homebound older adults. Front Public Health. 2017;5:54.

52. Berg Balance Scale. Rehabilitation measures database; 2010. Available from: http://www.rehabmeasures.org/Lists/RehabMeasures/PrintView. aspx?ID=888. Accessed May 28, 2016.

53. United Nations. World Population Prospects: The 2017 Revision, Key Findings and Advance Tables. Vol Working Paper No ESA/P/WP/248. New York, USA: United Nations, Department of Economic and Social Affairs, Population Division; 2017.
Clinical Interventions in Aging

\section{Publish your work in this journal}

Clinical Interventions in Aging is an international, peer-reviewed journal focusing on evidence-based reports on the value or lack thereof of treatments intended to prevent or delay the onset of maladaptive correlates of aging in human beings. This journal is indexed on PubMed Central, MedLine,

\section{Dovepress}

CAS, Scopus and the Elsevier Bibliographic databases. The manuscript management system is completely online and includes a very quick and fair peer-review system, which is all easy to use. Visit http://www.dovepress. com/testimonials.php to read real quotes from published authors. 